Roberto de Oliveira Campos, Embaixador do Brasil em Londres e ex-Ministro do Planejamento.

\title{
O Fim sem fim do capitalismo
}

- A história não é dialética e as coisas também não se passaram como previa Marx.

- O neomonetarismo ressurgiu com a renitência da inflação e a incapacidade dos keynesianos.

- O marxismo é uma técnica de conquista do poder, mas não de organização do desenvolvimento.

Nem o capitalismo e nem o socialismo subsistem em sua forma pura, mas não se deve exagerar na tese da convergência dos dois sistemas. As diferencas continuam dramaticamente perceptíveis nas zonas de confrontação: Alemanha Ocidental versus Alemanha Oriental, Coréia do Norte versus Coréia do Sul, China Continental versus Taiwan e assim por diante.

Simplificadamente, diz o embaixador Roberto Campos, poderiam ser apontadas duas diferenças básicas entre os dois sistemas. A primeira é que as "economias de mercado" tendem a ser politicamente pluralistas, enquanto as "economias de comando" são basicamente monistas, porque o Partido define os valores econômicos, políticos e sociais. A segunda é que na postulação socialista o importante é a distribuição, antes mesmo do que a produção.

Esta face do socialismo explica em parte o fascínio que exerce sobre muitos cristãos, os quais se esquecem da outra face do sistema, o antiespiritualismo implícito no materialismo dialético.

No entanto, diz Campos, apesar desse fascínio do socialismo e de ter o seu fim profetizado insistentemente, o capitalismo tem sobrevivido e evoluido. Por quê? Possivelmente, porque a economia de mercado é - como afirmou Hayek - o único sistema compatível com a liberdade do individuo. Assim, sobrevivente de inúmeras crises no passado, o capitalismo não deixa dúvida de que superará também a atual, a da "estagflação". 
A crise atual tem provocado uma desordem conceitual nas teorias econômicas, com controvérsias sobre a dosagem das medidas de combate à inflação, o debate entre monetaristas e keynesianos, e o surgimento de novas teorias. Mas, lembra Campos, se as economias de mercado estão presas de alguma perplexidade, o quadro não é nada melhor nas socialistas.

"A única coisa errada com a palavra 'revolução' é que tem um ' $r$ ' demais".

Houphonet-Breigny

Poucas coisas têm sido mais profetizadas do que o fim do capitalismo. Parafraseando Mark Twain, pode-se dizer que as notícias de sua morte são algo exageradas. Se duas lições a História nos ensina é, primeiro, que a História não é dialética: "O socialismo não sucedeu ao capitalismo", para usar a expressão de Daniel Bell. E, segundo, que a crise do socialismo parece hoje mais séria do que a do capitalismo. As coisas não se passaram exatamente como previa Marx. Não houve a "pauperização" do proletariado. O capitalismo monopolista sobreviveu à perda dos impérios. O socialismo não surgiu do proletariado industrial amadurecido, mas resultou do comando de intelectuais revolucionários sobre massas primitivas. O Estado não feneceu nos países que supostamente eliminaram o conflito de classes.

De um simples dispositivo de espoliação econômica - feudal, burguesa ou industrial - , o capitalismo evoluiu para transformar-se num sistema trinitário, com três vetores distintos em tensão criadora pontilhada de avanços e retrocessos: o aspecto econômico, o político e o cultural. O socialismo marxista, ao invés, partindo de uma ampla análise social, tornou-se um sistema monístico, em que esses diferentes valores se unificam e confundem, em rigidez pragmática. O socialismo, que nascera como ciência, virou religião. O capitalismo, que parecia simples obsessão econômica, absorveu valores do credo liberal, e revelou-se politicamente mais flexível e culturalmente mais diversificado. Nenhum dos dois sistemas hoje existe, obviamente, em sua forma pura, o que torna os termos "capitalismo" e "socialismo" simplificações duvidosas. Mas não se deve exagerar a convergência dos dois sistemas. As "economias de mercado" são perfeitamente diferenciáveis das "economias de comando", ainda que as primeiras tenham absorvido graus intensos de intervenção governamental e as segundas comecem a admitir os sinais do mercado no tocante a precos e incentivos. Isso é dramaticamente perceptível nas zonas de confrontação: Alemanha Ocidental "versus" Alemanha Oriental, Coréia do Norte "versus" Coréia do Sul, China Continental "versus" Taiwan e assim por diante.

Se quisermos, para simplificar as coisas, especificar as diferenças que permanecem fundamentais, citemos duas. A primeira é que as "economias de mercado" tendem a ser politicamente pluralistas, enquanto as "economias de comando" são basicamente monistas, isto é, o Partido define os valores econômicos, políticos e sociais. Uma segunda espécie de "marca do berço" é, como disse Irving Kris- 
tol, que na postulação socialista o importante é a distribuição, antes que a produção. Com isso elide, ou pensa elidir, o problema vital dos "incentivos" materiais. Pequenas sociedades, como os "kibutzim" de Israel e os mosteiros medievais, podem assim funcionar. As grandes sociedades perdem eficiência sem incentivos materiais e individuais. A preocupação distributiva explica em parte o secreto fascínio que o socialismo exerce sobre muitos cristãos, que assimilam distribuição à caridade. A tal ponto que se esquecem da face inaceitável do socialismo, isto é, seu antiespiritualismo de origem, implícito no materialismo dialético.

\section{A busca de raízes éticas}

Se o capitalismo, ou melhor, as "economias de mercado" têm sobrevivido às crises profetizadas por Marx, assim como às "contradições culturais" denunciadas por Daniel Bell, resta saber a que necessidade básica correspondem. Para Hayek, a explicação é simples. Reside em ser o único sistema compatível com a liberdade do indivíduo. E a liberdade, definível como a "ausência de constrangimento", é mais fundamental que a justiça, pois que esta depende de uma impraticável avaliação de mérito. Uma sociedade livre pode ser justa, enquanto uma sociedade não-livre nunca é justa, pois nega ao indivíduo a oportunidade de auto-realização.

Poucos têm hoje a coragem libertária de Hayek e preferem assim buscar outras justificativas para o "ethos capitalista", em face da crueldade do mercado. Irving Kristol, por exemplo, lembra, sem endossá-las, três explicações tradicionais:

- A ética protestante, ou seja, o conceito weberiano de que o sucesso econômico se justifica em função do exercício de virtudes pessoais, como a diligência, a sobriedade, a ambição honesta. (Esqueçamos, por inoportuno discuti-las, as teorias antiweberianas de que o capitalismo comercial nasceu nas cidades italianas e a organizacão do trabalho horário nos mosteiros medievais, antecedendo-se à ética calvinista).

- A ética darwiniana, segundo a qual o sucesso representa uma solução natural, pela sobrevivência dos mais capazes.

- A ética tecnocrática, segundo a qual o mercado organiza sua própria meritocracia e premia a liderança em função da "performan$\mathrm{ce}^{\prime \prime}$.

Nenhuma dessas explicações chega a constituir uma teologia moralmente tranqüilizadora, comparável ao fervor dogmático do socialismo.

O fato é que, seja pelas crueldades do mercado - onde fatores acidentais, como a herança, ou imperfeições políticas, como a discriminação racial, criam desigualdades chocantes - , seja pelo contágio de pregação socialista (que melhora e igualdade mas retarda a eliminação da pobreza), o capitalismo moderno desenvolveu sua própria "angst", uma espécie de complexo de culpa. Exemplos desse complexo de culpa são a reação contra o "consumismo" e a "depredação ecológica." 
Isso revela no sistema capitalista, ao mesmo tempo, debilidade ideológica (que o torna menos exportável) e flexibilidade pragmática (que o torna mais durável). Donde poder-se falar hoje nas "economias de mercado corrigido", nas quais o mercado sofre intervenções que refletem as contínuas tensões resultantes daquilo que se poderia chamar o "tríplice compromisso" entre riqueza individual, eqüidade social e liberdade política. O mercado privado seria o criador de riqueza; o governo, o promotor de eqüidade; e o sistema democrático, o preservador da liberdade. A sucessão de fases intervencionistas e libertárias na Europa Ocidental, assim como nos Estados Unidos, caracterizadas pela alternância de partidos sociais-democráticos ou conservadores, conforme predominem preocupações produtivistas ou distributivistas, denota as cambiantes predominâncias dos elementos constitutivos do tríplice compromisso.

\section{A superposição de crises}

Tendo sobrevivido a inúmeras crises no passado, inclusive ao vendaval da grande depressão na década de 30 , há poucas dúvidas de que as economias de mercado sobrevivam à presente crise de "estagflação". Registrem-se, entretanto, três complicadores. Primeiro, a adaptação ao choque do petróleo requer ajustamentos de estrutura, e não apenas remédios de conjuntura. Segundo, há uma grande perplexidade doutrinária, pelo desaparecimento de antigas certezas sobre métodos de gerenciamento global da economia. Terceiro, as sociedades ocidentais, habituadas a um quarto de século de avanço contínuo na renda real, têm percepção mais aguda daquilo que se chama o "índice de desconforto", medida composta do grau de inflacão e do índice de desemprego, aos quais se agrega o novo conceito de deterioração ambiental. Da mesma maneira que os países em desenvolvimento foram sacudidos pela "revolução das expectativas crescentes", os países industrializados foram atacados pela presunção de "direitos crescentes" ("the evolution of rising entitlements").

Limitaremos nossa análise à desordem conceitual que se instalou nas teorias econômicas, onde se podem citar quatro controvérsias intensificadas pela teimosa persistência da "estagflação":

- a controvérsia entre gradualismo e tratamento de choque;

- o debate entre monetarismo e keynesianismo;

- as novas teorias de "administração da oferta" (supply side economics); e

- a ressurreição dos ciclos de longo prazo la teoria da "onda larga" de Kondratieff, economista russo da década de 20).

A controvérsia do gradualismo "versus" tratamento de choque torna-se cada vez menos interessante. O bom senso indica que o tratamento de choque só não transpõe o limite de tolerância política se a inflação é moderada e se as expectativas não se tornaram cronicamente viciadas, de modo a permitir que o trauma recessivo seja curto. Caso contrário, as sociedades estão condenadas ao gradualismo. O que é importante, como nota o professor William Fellner, é que seja um "gradualismo a velocidade perceptível", isto é, suficiente para modificar as expectativas. 
A reativação da controvérsia entre monetarismo e keynesianismo foi conseqüência direta da "estagflação". Por longo tempo no pós-guerra, o keynesianismo ganhou foros de ortodoxia, principalmente no mundo anglo-saxão (no continente europeu a escola austríaca manteve viva a tradição monetarista). A renitência da inflação e a incapacidade do keynesianismo de debelá-la provocaram uma ressurreição neomonetarista, com experimentos monetaristas ensaiados na Inglaterra e nos Estados Unidos, encorajados pela evidência de que os países mais bem-sucedidos na luta contra a inflação - Suíça, Alemanha e Japão - foram os que menos se expuseram à contaminação keynesiana.

A "nouvelle vague" nos Estados Unidos é a administraçăo da oferta - "supply side economics". A ênfase sobre a oferta é válida se interpretada como complemento, e não como substitutivo da "administração da procura". A "supply side economics" é, entretanto, mais que simples metodologia. Aspira a ser uma filosofia de reabilitação do "ethos" capitalista, pela liberação das energias do produtor, restauração de incentivos à poupança e produtividade, estímulo à concorrência, redução de interferência governamental, seja assistencial, seja regulatória. (Os exageros da mania ecológica - a ecomania - nos Estados Unidos encareceram e retardaram investimentos).

A intratabilidade da atual fase de "estagflação" ressuscitou veIhas teorias sobre ciclos econômicos, que a contínua prosperidade do pós-guerra parecia haver arquivado. Segundo o professor Walter Rostow, a explosão dos preços de trigo, petróleo e outras matériasprimas em 1972/73 prenuncia o advento de uma nova onda larga da conjuntura, o quinto ciclo Kondratieff, marcado pela relativa escassez de matérias-primas, especialmente energia. Como é sabido, o economista russo Kondratieff (que, segundo Soljenitsyn, teria morrido num gulag), escrevendo na década de 20, identificara no exame de séries estatísticas, relativas à Grã-Bretanha, França e Estados Unidos, a existência de ciclos ascendentes e descendentes de produção e precos, num espaco de quarenta a cinqüenta anos entre 1790 e 1920. Na extrapolação de Rostow, a grande depressão dos anos 30 marcaria a fase descendente do terceiros Kondratieff, enquanto o período recente $(1972 / 79)$ marcaria o começo do ramo ascendente do quinto Kondratieff. Nessa visão, as crises não seriam o canto de cisne do capitalismo, e sim episódios de uma tendência evolutiva. É interessante anotar os pontos de convergência entre uma interpretação à la Kondratieff e a presente busca de uma teoria de "administração da oferta". Pois se estamos no limiar de um novo ciclo Kondratieff, caracterizado pela relativa escassez de produção primária e energética, a política adequada não deveria ser macroeconômica, nem no sentido monetarista de simples administração de procura, nem no sentido keynesiano de estímulo global a investimentos, senão que direcionada seletivamente para o aumento da oferta setorial de matériasprimas e energias alternativas. A reorientação seletiva de investimentos, no sentido do rompimento de gargalos, representaria uma conciliação entre a necessidade antiinflacionária de conter a demanda global e a necessidade anti-recessiva de estimular a oferta.

Mas, se o capitalismo hodierno superpõe às perplexidades da 
"estagflação" uma desorientação conceitual, o panorama não é nada melhor no campo socialista. O marxismo deixou de ser ciência para transformar-se em dogma. Sua eficácia ficou limitada à quebra de moldes feudais em sociedades primitivas. É uma técnica de conquista do poder, mas não de organização do desenvolvimento. O planejamento centralista infirmou a criatividade tecnológica (exceto, no caso soviético, no tocante à tecnologia militar e espacial), enquanto o emudecimento dos sinais do mercado entorpeceu a agricultura, os serviços e as indústrias de bens de consumo. A falta do elo dos incentivos na corrente produtiva acabou prejudicando a distribuição e tornando as economias socialistas menos desiguais, porém globalmente mais pobres do que as economias de mercado. O êxito do desempenho econômico tem estado na razão inversa, e não na razão direta da ortodoxia socialista. Uma visão retrospectiva justifica a dúvida se a Revolução Socialista de 1917, pago o pesado preço de sua brutalidade política, conseguiu no fundo acelerar o desenvolvimento russo, comparativamente ao processo evolutivo das democracias ocidentais. Talvez Houphonet-Breigny, o astuto presidente da Costa do Marfim, tenha feito mais que uma piada ao dizer que há um " $r$ " sobrando na palavra" revolução"... 